\title{
Del pensamiento de Kierkegaard y Rimas de Bécquer a la cosmovisión de Unamuno: la teoría y la práctica del existencialismo español ${ }^{*}$
}

\author{
From the ideas of Kierkegaard and Rimas of Bécquer to the \\ views of Unamuno: the theory and practice of spanish \\ existencialism
}

VLADIMER LUARSABISHVILI**

\begin{abstract}
Resumen: En nuestro artículo intentamos acercarnos al tema del existencialismo español, y a la visión filosófica de Miguel de Unamuno en particular. Entendiendo las razones del filosofar y revisando los vínculos que existen entre la filosofía y la literatura, investigamos los gérmenes del existencialismo romántico (de Sören Kierkegaard) y pre-existencialismo literario (de Gustavo Adolfo Bécquer) que cumplen una función precursora del existencialismo filosófico cultivado en los textos de Unamuno, tanto literarios como documentales.
\end{abstract}

Palabras clave: Unamuno, Kierkegaard, Rimas de Bécquer, existencialismo.

\begin{abstract}
In our article we try to approximate to the theme of spanish existencialism and the views of Miguel de Unamuno in particular. Evaluating the reasons of philosophizing and revising the relation between phylosophy and literature, we investigate the origins of romantic existencialism (of Sören Kierkegaard) and literary pre-existencialism (of Gustavo Adolfo Bécquer) which has the precursor function of phylosophical existencialism cultivated in Unamuno's literary and documentary texts.
\end{abstract}

Keywords: Unamuno, Kierkegaard, Bécquer's Rimas, existencialism.

Recibido: 09/07/2018. Aceptado: 20/12/2018.

* Este trabajo es resultado de la investigación realizada en el proyecto de investigación METAPHORA, de Referencia FFI2014-53391-P, financiado por la Secretaría de Estado de Investigación, Desarrollo e Innovación del Ministerio de Economía y Competitividad de España.

** Doctor por la Universidad Autónoma de Madrid. Actualmente es profesor en la New Vision University (Tbilisi, Georgia) y profesor invitado en la Universidad de La Frontera (Temuco, Chile). Correo electrónico: vluarsabishvili@newvision.ge. Dos son sus líneas de investigación básicas: la poética de Gustavo Adolfo Bécquer y Miguel de Unamuno, por un lado, y las relaciones entre la filosofía, retórica, literatura e historia, por otro. Últimas publicaciones: "La ironía: sobre la evolución histórica de la noción", Dicenda. Estudios de lengua y literatura españolas, 37, 2019, 185-198; "Un intento de traducción poética: Miguel de Unamuno en georgiano" (Algunos ejemplos)”, Hermēneus, 21, 2019, 625-631; “Análisis interdiscursivo, Retórica, Traducción e Intertextualidad", Archivum, LXVIII, 2018, 93-114; "Del Romanticismo al Existencialismo: ironía, el yo, amor, pasado y libertad", Boletín Hispánico Helvético, 31, 2018, 55-65; "La sensación de la soledad en las Rimas de Bécquer. Aproximación a la poesía metafísica”, en Revista de Filosofía. Madrid: UCM, 42 (2): 247-259, 2017; "Sobre la traducción de los textos filosóficos", en Tonos Digital, 32: 1-14, 2017; "La traducción de la metáfora - una reflexión del traductor”, en Revista de Investigación Lingüística, 19: 251-268, 2016. 


\section{Introducción}

Hace tiempo que nuestra atención ha sido atraída por la relación entre la poesía de Bécquer y el pensamiento de Unamuno; en un trabajo anterior hemos mostrado los vínculos que existen entre la ironía romántica en las Rimas de Bécquer y el pensamiento crítico de Unamuno ${ }^{1}$ y hemos estudiado el síntoma universal del romanticismo - la soledad - en las Rimas y Leyendas de Bécquer y la lágrima solitaria en las Leyendas de Bécquer ;ªl mismo tiempo, existen trabajos que niegan la influencia directa de los textos de Bécquer en la obra de los autores posteriores (Acereda, 1999, 2000). Partiendo de lo mencionado, intentamos mostrar la relación que existe entre el romanticismo y el existencialismo español.

Pensamos que nuestra investigación puede ayudar a llenar el vacío que existe en el terreno del entendimiento no sólo de la carga filosófica de la literatura romántica española (de Bécquer en particular), sino que también puede facilitar la comprensión de los perfiles románticos del pensamiento filosófico español (de Unamuno).

Hemos dividido nuestro artículo en tres partes: en la primera brevemente observamos la relación entre la literatura y la filosofía; en la segunda destacamos las características existencialistas de Kierkegaard en las Rimas de Bécquer y analizamos las ideas precursoras del romanticismo español cultivadas en los textos de Unamuno, y en la tercera ofrecemos las conclusiones finales de la investigación.

\section{La relación entre la literatura y la filosofía}

Ya en las obras de los clásicos antiguos encontramos una relación entre la literatura y la filosofía. Así, Aristóteles distinguía las funciones del historiador y el éeta destacando el carácter filosófico de la poesía por su habilidad de narrar "más bien lo general": "La diferencia estriba en que uno narra lo que ha sucedido, y el otro lo que podría suceder. De ahí que la poesía sea más filosófica y elevada que la historia, pues la poesía narra más bien lo general, mientras que la historia, lo particular" (Aristóteles, Poética, 1451b, 56). Esta visión aristotélica está interpretada por el profesor Antonio García Berrio, que subraya la posibilidad que otorga la poesía al hombre de duplicar la realidad: “[...] la Poética es para Aristóteles una facultad complementaria del conocimiento filosófico. La poesía supone la posibilidad que el hombre tiene de duplicar la realidad, creando a través de la imitación o mímesis un mundo ficcional que él mismo estructura y gobierna" (García Berrio, 1994, 27).

1 Luarsabishvili, V. (2012), "La ironía romántica en las Rimas de Bécquer”, en AdVersuS, IX, pp. 136-149; Luarsabishvili, V. (2015), "La sensación de la soledad en las Leyendas de Bécquer”, en AdVersuS, XII, pp. 122-136; Luarsabishvili, V. (2016), "La lágrima solitaria en las Leyendas de Bécquer”, en AdVersuS, XIII, pp. 167-177; Luarsabishvili, V. (2017), "La sensación de la soledad en las Rimas de Bécquer. Aproximación a la poesía metafísica", en Revista de Filosofía, no 42 (2), pp. 247-259.

2 Luarsabishvili, V. (2015), "La sensación de la soledad en las Leyendas de Bécquer”, en AdVersuS, XII, pp. 122-136. 
Después de la reforma platónica de convertir la filosofía en literatura, muchas ideas filosóficas penetran en la literatura. Quitando los vestidos de sabiduría, adquieren rasgos estéticos. Pero lo inteligible queda como material primordial que evoluciona en el contexto literario. De aquí el parentesco de reflexión entre los discursos filosófico y literario. Varios autores destacan la relación que existe entre la novela y la filosofía, subrayando la posibilidad del texto literario cultivar distintas corrientes filosóficas. María Zambrano indicaba el papel de la novela en el desarrollo de la filosofía española sirviéndose por ejemplo de Cervantes e igualando la novela española a la filosofía europea (Zambrano, Apud Mora García, 2001, 35). El profesor José Luis Mora García interpretando la vision de María Zambrano subraya un desarrollo del pensamiento desde el Renacemiento hasta el Barroco y lista los puntos decisivos de los cambios mencionados indicando el papel de la revisión de los géneros de expresión y la importancia de la novela como ejemplo de diversidad y unidad (Mora García, 2001, 35-37). El profesor ve la literatura "en el horizonte de la filosofía" que acude en nuestra ayuda para explicar lo escondido en nuestro tiempo, para encontrar la verdad y comprender la realidad:

Desde este punto de vista, pues, la literatura reaparece en el horizonte de la filosofía cuando ésta da muestras de inadeacuación para explicar en términos de globalidad una situación, algo que se ha agudizado en nuestro siglo aunque viniera de largo. Vivimos tiempos de literatura, es decir, de grandes dificultades para construir una visión de totalidad, aspiración vieja de la vieja filosofía. La última crisis de unidad ha estallado más recientemente, y aunque estaba germinalmente apuntada con anterioridad, no ha podido ser detectada sino desde las últimas décadas del XIX y a lo largo de todo el XX y por eso los filósofos nos hemos lanzado a hablar de literatura con un afán autoexplicativo, en defensa propia muchas veces, en discursos circulares que concluyen en el punto de partida, es decir, en la supuesta superioridad de la filosofía frente a este otro lenguaje que compite, también, por ofrecer verdad, por dar cuenta de la realidad y tratar de comprenderla (Mora García, 2001, 35).

Revisando las ideas sobre el tema, podemos concluir que la filosofía y la literatura son dos esferas con la misma trayectoria cultural, humanística y religiosa. Los métodos de la expresión, los fines perseguidos y las características que poseen estos dos ambientes se cruzan con frecuencia y a menudo se ayudan una a otra para reflexionar sobre la verdad metafísica. A pesar de que en la misma época puede desarrollarse una más y otra menos (como literatura, la novela, en España y filosofía en otros países de Europa), la función creativa de ambas es innegable. Lo trágico y lo cómico no son sólo dos caras de la misma moneda que puede representar las facetas diferentes del entendimiento humano (vidamuerte, realidad-ficción, etc.), sino que explican e interpretan la contemporaneidad del individuo que reflexiona. Así, el pensar se convierte en la tradición que es lo contemporáneo y no lo pasado o futuro. Y lo que es más importante es que con el cambio del tiempo no agotan las posibilidades de la interpretación diferente, cuando el mismo texto puede ser interpretado con la radical diferencia, desde distintos prismas. Y un buen ejemplo de lo dicho es, sin duda alguna, el Quijote. 


\section{Las características existencialistas de Kierkegaard en las Rimas de Bécquer y su papel precursor en la formación de la cosmovisión unamuniana}

Empezamos este apartado con la búsqueda de las características del existencialismo romántico (de Kierkegaard) en las Rimas de Bécquer. ${ }^{3}$ Pensamos que en los textos del poeta sevillano se hallan las huellas del existencialismo metafísico que posteriormente habían sido cultivadas en los textos del filósofo bilbaíno. Entre las nociones de tal índole son los conceptos de la angustia, el sueño y la libertad.

Según Kierkegaard, la angustia es una característica del hombre que condiciona su originalidad. Su profundidad depende de la originalidad del este y está vinculada con la noción de pecaminosidad. Podemos concluir que la peculiaridad del hombre de poder experimentar la angustia es lo que le puede distinguir del animal (Kierkegaard, 2013, 121-122).

Decía Kierkegaard que angustia se parece a nostalgia y nos puede servir de señal, de estado que anuncia la crisis en la que se encuentra el individuo y su deseo de salir de ella: "La expresión de una nostalgia semejante es la angustia; pues en la angustia se anuncia aquel estado del cual el individuo desea salir, y precisamente se anuncia porque el solo deseo no basta para salvarlo" (Ibid., p. 131). Al mismo tiempo, como indica J. C. Lago Bornstein: "Para Kierkegaard la angustia proviene de la antinomia constitutiva del hombre considerado como espíritu, síntesis de lo eterno y de lo temporal" (1986: 63). Relativo a lo mostrado, recordamos la rima LXVIII de Bécquer ${ }^{4}$ en la que el sueño becqueriano anuncia, como el texto de Kierkegaard, un estado del alma ("de un amargo placer henchirse el alma"). El sueño continúa al despertar tomando forma de angustia. Bécquer entiende la naturaleza de la angustia (que es un placer amargo) y probablemente quiere salir de ella (porque el sueño es triste). Como según Kierkegaard "el solo deseo no basta para salvarlo", lo que le queda a Bécquer son lágrimas (“isé que aún me quedan lágrimas!”).

Un paso hacia la libertad es el entendimiento de la propia angustia que es comparable con el vértigo. Al mirar en nuestro fondo, comprendemos nuestra debilidad, la impotencia humana menos fuerte que se pierde por no poder alcanzar la libertad (Ibid., p. 136). En la rima LII Bécquer busca un espacio dónde el mismo vértigo le pueda arrancar la memoria para no quedarse solo con el dolor que experimenta (Bécquer, 2003, 53). Así, la angustia, el abismo y el vértigo hacen patente la necesidad de la libertad que es una caracterización del hombre y de donde se derivan las propias posibilidades del individuo. En la Rima XLVII, los "ojos" desempeñan un papel importante también en modo de entendimiento becqueriano ("o con los ojos/o con el pensamiento"). La diferencia entre los autores la podemos encontrar en el camino de llegar a la libertad: Kierkegaard camina hacia la libertad por el pensamiento filosófico (subrayando el deseo del individuo que es una suma del carne y alma unidas por espíritu), (Kierkegaard, 2013, 104), mientras que Bécquer llega al abismo "de un corazón". Esto último no nos sorprende pues Bécquer es un autor romántico con rasgos metafísicos pero con plano común literario y no filosófico.

3 Seguiremos, para las citas de la obra de Bécquer, la siguiente edición: Bécquer, G.A. (2003), Rimas y Leyendas, Madrid: Alba.

4 Ibid., p. 60. 
Reflexionando sobre el secreto del espíritu, Kierkegaard compara la belleza del varón con la de la mujer subrayando la importancia de la faz del primero y el papel de la sabiduría en el caso de la mujer, representado tanto por un silencio como por una "suprema belleza" de la mujer (Ibid., 144). Lo mismo señala Bécquer en la rima XXXIV (Bécquer, 2003,45-46), declarando que la mujer guarda el enigma "callando" y oponiéndola con las otras que se expresan mediante las palabras. Entonces, estar callado o guardar silencio indica la sabiduría de la mujer, que posee cierto valor para el poeta. En este poema también encontramos la metáfora universal del romanticismo: cada lágrima (la lágrima solitaria según Russel P. Sebold) ${ }^{5}$.

En la rima XI Bécquer rechaza lo real, es decir, los distintos tipos de mujeres llenas de goces y dichas y desea encontrar la que sea incorpórea e intangible, un producto de la niebla, de la luz, a pesar de que ella no puede amar al poeta; parece que la vida de Bécquer estuvo llena de tristeza y soledad, a las que el poeta prestaba poca atención viviendo con lo pensado, con lo no real e imaginario. Efectivamente, Julio Nombela contaba sobre la vida en que vivía Bécquer, que en lugar de encontrarse en la vida real, se presentaba en el mundo imaginario, lleno de propios pensamientos, ideas y sentimientos (Nombela, Apud Sebold, 1982, 28).

Podemos concluir que las características del existencialismo romántico de Kierkegaard son evidentes en las Rimas de Bécquer. La aspiración hacia la angustia, el sueño y la libertad (expresada mediante diferentes modos de expresión), cuya importancia subraya Kierkegaard, son vigentes en los textos del poeta sevillano. No hay que olvidar la importancia del misterio, tanto filosófico, como poético. El sentido íntimo que guía al espíritu hacia la libertad, está escondido en el individuo que busca la inmortalidad, lo que veremos adelante reflexionando sobre el mismo tema en la interpretación unamuniana.

Existen muchas referencias de la influencia de Kierkegaard sobre la formación de la visión de Unamuno, ${ }^{6}$ incluyendo las investigaciones de J. A. Collado (1962), P. Cerezo (1996) y B.Vauthier (2002). Uno de los conceptos estudiados en ambos pensadores es el concepto de la verdad. Lo mencionado fue expuesto en el artículo de Delia Aguiar Baixauli tutilado "La verdad en Kierkegaard y Unamuno" indicando que:

Tanto Kierkegaard como Unamuno perseguían la verdad como autenticidad, como ejercicio de decirse a sí mismo, aunque Kierkegaard estaba condicionado por la existencia de Dios personal que, mediante órdenes y mandatos, educaba al hombre y le hacía convertirse en sí mismo. [...] En Unamuno, por el contrario, Dios no era un ser objetivo, sino una creación por parte del hombre en función de sus necesidades,

5 Sobre los síntomas y metáforas del romanticismo: Sebold, R. P. (2011),“La cosmovisión romántica: siete síntomas y cinco metáforas”, en Castilla. Estudios de Literatura, 2, pp. 311-323.

6 Fasel, O. A. (1955), "Observations on Unamuno and Kierkegaard”, en Hispania, 38, 4, pp. 443-450; Tornos, A.M. (1962), "Sobre Unamuno y Kierkegaard”, en Pensamiento, 70, 18; Weber, R. H. (1964), "Kierkegaard and the Elaboration of Unamuno's Niebla”, en Hispanic Review, 32, 2, pp. 118-134; Roberts, G. (1986), Unamuno: afinidades y coincidencias kierkegaardianas, Society of Spanish and Spanish-American Studies; Evans, J. E. (2006), "Kierkegaard, Unamuno, and Don Quijote as the Knight of Faith", en Symposium, 60, pp.3-16; Evans, J. E. (2005), "Passion, Paradox, and Indirect Communication. The Influence of 'Postscript' on Miguel de Unamuno", en Kierkegaard Studies. Yearbook 2005 (Cappelørn, Niels Jørgen, Hermann Deuser \& K. Brian Söderquist, eds.), Berlin/New York, pp. 137-152; Ardila, J.A.G. (2008), "Nueva lectura de Niebla: Kierkegaard y el amor", en Revista de Literatura, enero-junio, vol. LXX, no 139, pp. 85-118. 
creación que el propio autor equipara con el simbolismo de la historia de Abisag, la joven que daba calor con su cuerpo al viejo rey David, manteniéndolo con vida. [...] Kierkegaard poseía un método para transmitir esas verdades, basando en el método socrático y en "engañar" de algún modo a su "discípulo", para que este quede abierto a la correcta version, mientras que Unamuno no empleaba más método que la escritura y las verdades descarnadas, expresadas directamente y bajo el lema bíblico “quien quiera oír que oiga” (Aguiar Baixauli, 2014, 103-104).

Al mismo tiempo, el filósofo bilbaíno utilizaba en sus textos algunas citas de los textos de Bécquer (lo que Unamuno se percató de la modernidad de Bécquer muestra Bénédicte Vauthier en su artículo dedicado a la poética del filósofo bilbaíno (Vauthier, 2009)). Una de las últimas referencias de tan índole, indicando la intertextualidad de tanto Kierkegaard como de Bécquer, es un artículo recientemente publicado de Juan Antonio Garrido Ardila que observa como ejemplo la novela de Unamuno Niebla entre otros textos:

No solamente experimenta Unamuno con esa corriente novelística áurea, sino que construyó Niebla sobre una fabulosa estructura de referencias literarias que la hacen, quizá, la novela más intertextual de la literatura española contemporánea. En Niebla, novela metafísica como se la designa en el prólogo, se parodia la corriente naturalista (novelistas pornográficos por un lado, y Galdós por otro); se despliega toda la enjudia filosófica que Unamuno había vertido en Del sentimiento trágico de la vida de 1913; se recrea el Diario del seductor de Kierkegaard; se emplean motivos becquerianos, y se recogen y perfeccionan las innovaciones técnicas que el mismo Unamuno había empleado en Amor y pedagogía y que tenían como precursores, en España, a Ganivet y a las novelas espiritualistas de gentes como Pardo Bazán y Clarín [...] En definitiva, las novelas de Unamuno se distinguen como flor entre las más originales e innovadoras de nuestro tiempo, y como las más densas filosóficamente, además de estar escritas en un estilo único. Unamuno es, pues, origen y sima de la novela contemporánea española (Garrido Ardila, 2014, 6).

Buscando los inicios de la reflexión sobre la tragedia, recordamos las palabras de Aristóteles, para quien la tragedia es la imitación de la vida, de la acción, cuyas personajes pueden ser felices o infelices: "pues la tragedia es imitación no de personas, sino de acción y de vida, y la felicidad y la infelicidad están en acción, y el objetivo es un tipo de acción, no la calidad. Y los personajes son tales o cuales según su carácter; pero según las acciones son felices o lo contrario" (Aristóteles 1450a, p. 49).

Con la relación de lo mencionado, recordamos la rima XXXI de Bécquer (Bécquer, 2003, 45 ), en la que el poeta ve la vida como tragedia ("trágico sainete") que está llena de las contradicciones ("lo cómico y lo grave confundidos...") lo que tanta importancia posee en textos de Miguel de Unamuno. La tragedia es lo mismo para Unamuno: es una lucha (acción según Aristóteles), pero una lucha sin nada, una contradicción (Unamuno, 2005). Esta acción aristotélica y lucha unamuniana nos guían al existencialismo filosófico con sus definiciones y finalidades. En concreto, Unamuno se pregunta por su propia existencia, profundizando no sólo en la pregunta sobre el nacimiento, sino en el problema del morir, destacando diferentes 
posibilidades de estar muerto y añadiendo el componente de la lucha a la más pesimista de las tres. La misma pregunta se hace Bécquer subrayando que anda "al acaso" y sin finalidad definitiva en su vida - leemos la rima II: "[...] eso soy yo, que al acaso/cruzo el mundo, sin pensar/de dónde vengo, ni dónde/mis pasos me llevarán" (Bécquer, 2003, 26). La idea becqueriana de no saber a dónde le llevarán sus pasos interesa a Unamuno, que descubre la importancia de la finalidad, del "para qué" en su vida (Unamuno, 2011, 76). A este "para qué" sigue un entendimiento de la vida, de su naturaleza temporal, que pasa: “¡Todo pasa! Tal es el estribillo de los que han bebido de la fuente de la vida, boca al chorro, de los que han gustado del fruto del árbol de la ciencia del bien y del mal" (Kierkegaard, 2013, 82).

La distinción entre los puntos de vista de Kierkegaard y de Unamuno en torno a la existencia estriba en que para Kierkegaard

el tema de la existencia, simplificando la cuestión, tiene una connotación precisa y es la de ser finalmente una existencia religiosa. Para Kierkegaard existir es, en última instancia, existir ante Dios. [...] Unamuno, por su parte, desarrolla el tema de la existencia ya desde el comienzo de su producción y continúa en la misma línea a lo largo de toda su obra. Para él existir es obrar y existe todo lo que obra o todo lo que mueve a obrar (Lago Bornstein, 1986: 61-62).

Pero a pesar de tal visión Unamuno no puede recibir lo que pasa, lo que deja de existir y quiere ser siempre, pasarse por la eternidad. Unamuno no quiere morir, hasta el deseo de quererlo es insoportable para él. Pero esta muerte, esta sensación de ser siempre está vinculada con el arregosto de vivir. Y lo que es paradójico es que la liberadora es la muerte misma. Así, la angustia, el "para qué" y el intento de entender la vida, ocupan un lugar importante en el pensamiento del filósofo bilbaíno. La huida romántica, el temor por estar solo y la ironía se transforman en las herramientas del existencialismo, profundizándose durante la reflexión y convertiéndose en las meras contradicciones del pensamiento humano. Sin llegar a componer un sistema filosófico bien estructurado, Unamuno nos guía por los caminos del pensamiento propio y original, interpretando las mismas cosas desde los diferentes prismas.

\section{Conclusiones}

El sueño becqueriano se transforma en la angustia. Pero la angustia no es un estado del alma aceptable para Bécquer, por eso el poeta quiere salir de él. Al intertarlo, Bécquer entiende que el deseo supera sus propias posibilidades (por un agotamineto de las fuerzas, por una impotencia humana contra la realidad). De aquí nace el deseo de huir, de escapar de los acontecimientos vitales y encontrarse en el mundo ficticio e imaginario. Lo único que le relaciona con este mundo es el dolor con que quedarse solo le arranca al poeta el miedo. Encontrándose así en un estado medio - ni en este mundo ni en otro, Bécquer intenta entender dónde se halla, de dónde viene y adónde va.

Así, Bécquer crea un plano común por su naturaleza romántica (lágrimas, huida, angustia, dolor, etc.), pero empieza a cultivar algunas ideas del existencialismo romántico (angustia kierkegaardiana, mundo imaginario, un rechazo del mundo real, un intento de entender 
adónde va, etc.). Como una etapa del desarrollo, el existencialismo romántico español prepara un campo fertil para que el existencialismo metafísico español sea cultivado.

La diferencia, a mi ver, entre los dos escritores reside en el hecho de que Unamuno no se limita a una simple indicación del estado confundido en que se encuentra. Desarrollando las ideas existencialistas tanto propios como de los otros autores (por ejemplo, de Bécquer (las rimas LII y LXV)), el filósofo bilbaíno intenta comprender la naturaleza de lo real y de lo ficticio, añadiéndoles perfiles nuevos, de índole metafísica a los temas románticos. De esta manera, Unamuno desarrolla un plano común por su naturaleza filosófica, es decir existencialista, interpretando y profundizando las ideas del existencialismo romántico.

Lo que conecta a los dos escritores es una "personalización" del pensamiento, es decir, Bécquer pone su propia persona en el centro del universo como un autor romántico clásico, y Unamuno hace lo mismo como hombre mortal, relacionando su propia angustia con la muerte. El hecho de que la muerte posea un carácter liberador ayuda a Unamuno a entender la locura del Quijote y añadir nuevos perfiles al pensamiento. Basando su entendimiento en lo español y encontrando algunas ideas en Cervantes y San Juan de la Cruz, Unamuno forma una visión llena de contradicciones tomando por un punto de partida los diferentes prismas de la visión. ${ }^{7}$

\section{Referencias}

Acereda, A. (1999), “Bécquer: ¿Pórtico de la poesía española del siglo XXI? Una revisión metafísica de las RIMAS”, La Torre, Revista de la Universidad de Puerto Rico, nº13, pp. 483-504.

Acereda, A. (2000), "Darío moderno, Bécquer romántico. En torno a un lugar común en la modernidad poética en lengua española”, Cuadernos Americanos, nº 80, pp. 175-193.

Aguiar Baixauli, D. (2014), "La verdad en Kierkegaard y en Unamuno", ÉNDOXA: Series Filosóficas, $\mathrm{n}^{\mathrm{o}} 34$, pp. 87-104.

Aristóteles (2011), Poética, Madrid: Alianza Editorial.

Cerezo Galán, P. (1996), Las máscaras de lo trágico: filosofía y tragedia en Miguel de Unamuno, Madrid: Trotta.

Collado, J.A. (1962), Kierkegaard y Unamuno. La existencia religiosa, Gredos: Barcelona. García Berrio, A. (1994), Teoría de la Literatura, Madrid: Cátedra.

Garrido Ardila, J.A. (2014), "Miguel de Unamuno: Génesis de la novela contemporánea", Ínsula, no 807 , pp. 2-6.

7 El profesor Pedro Ribas indica la vacilación de los representantes de la Generación del 98 en cuanto al pasado de España, que ignoraban los noventayochistas y prestaban más atención al pasado: "Los aires renovadores venían de Europa. En el caso del modernismo catalán, el entusiasmo por Wagner y por Nietzsche indica que se miraba más hacia los valores de fuera que hacia la tradición propia. En el caso de la Generación del 98 la mirada hacia el pasado es bastante más ambigua. No les gusta a los noventayochistas la España que encuentran, pero no ven nada claro qué actitud tomar: por un lado, es demasiado importante el rico siglo de oro castellano, como se ve en los ensayos de Unamuno En torno al casticismo; por otro, hay que salir del anquilosamiento. La figura de don Quijote, en su mezcla esperpéntica de personaje del pasado y, a la vez, de luchador contra los dogmas de ese mismo pasado, parece uno de los símbolos que más certeramente permiten vislumbrar el rumbo seguido por los miembros de esa famosa Generación.” (Ribas, 1998, 55-70). 
Kierkegaard, S. (2013), El concepto de la angustia, Madrid: Alianza Editorial.

Lago Bornstein, J.C. (1986), "Unamuno y Kierkegaard: dos espíritus hermanos”, Anales del eminario de Metafísica, $\mathrm{n}^{\circ} \mathrm{XXI}$ : 59-71.

Mora García, J. L. (2001), "El valor filosófico de la literatura del 98”, en: Filosofía Hispánica Contemporánea: el 98, Actas del XI Seminario de Historia de la Filosofía española e iberoamericana (Universidad de Salamanca, 21 al 25 de septiembre de 1998), Fundación Gustavo Bueno, Salamanca 2001, pp. 33-63.

Ribas, P. (1998), “Contexto sociocultural de la generación del 98 (1895-1905)”, en Anuario Filosófico, n 31, pp. 69-70.

Sebold, R. P. (1982), Gustavo Adolfo Bécquer, Madrid: Taurus Ediciones.

Unamuno, M. de (2005), Del sentimiento trágico de la vida, Madrid: TECNOS.

Vauthier, B. (2002), "El arte de escribir de Miguel de Unamuno. Paralipómenos estílísticos. Unamuno y sus maestros", Cuaderno gris, n 6 (Ejemplar dedicado a: Unamuno y Europa: nuevos ensayos y viejos textos / coord. por Pedro Ribas Ribas), pp. 205-244.

Vauthier, B. (2009), "Releyendo Teresa. Rimas de un poeta desconocido presentadas y presentado por Miguel de Unamuno a la luz de una cuartilla inédita. Un alegato unamuniano a favor de la modernidad de Bécquer", en Miguel de Unamuno. Estudios sobre su obra. IV. Actas de las VII Jornadas Unamunianas, Salamanca, Casa-Museo Unamuno, 27 a 29 de septiembre de 2007, Ediciones Universidad de Salamanca, 2009. 
